\title{
Smooth Muscle Calcium and Endothelium-derived Relaxing Factor in the Abnormal Vascular Responses of Acute Renal Failure
}

\author{
John D. Conger, John B. Robinette, and Robert W. Schrier \\ University of Colorado Health Sciences Center, Veterans Administration Medical Center, Denver, Colorado 80220
}

\begin{abstract}
Abnormal renovascular reactivity, characterized by paradoxical vasoconstriction to a reduction in renal perfusion pressure (RPP) in the autoregulatory range, increased sensitivity to renal nerve stimulation (RNS), and loss of vasodilatation to acetylcholine have all been demonstrated in ischemic acute renal failure (ARF). To determine if ischemic injury alters vascular contractility by increasing smooth muscle cell calcium or calcium influx, the renal blood flow (RBF) response to reductions in RPP within the autoregulatory range and to RNS were tested before and after a 90 -min intrarenal infusion of verapamil or diltiazem in 7-d ischemic ARF rats. Both calcium entry blockers, verapamil and diltiazem, blocked the aberrant vasoconstrictor response to a reduction in RPP and RNS (both $P<0.001$ ).

In a second series of experiments the potential role of an ischemia-induced endothelial injury and of the absence of endothelium-derived relaxing factor (EDRF) production were examined to explain the lack of vasodilatation to acetylcholine. Acetylcholine, bradykinin (a second EDRF-dependent vasodilator), or prostacyclin, an EDRF-independent vasodilator, was infused intrarenally for $90 \mathrm{~min}$, and $\mathrm{RBF}$ responses to a reduction in RPP and RNS were tested in 7-d ischemic ARF rats. Neither acetylcholine nor bradykinin caused vasodilatation or altered the slope of the relationship between RBF and RPP. By contrast, prostacyclin increased RBF $(P<0.001)$, but did not change the vascular response to changes in RPP.

It was concluded that the abnormal pressor sensitivity to a reduction in RPP and RNS was due to changes in renovascular smooth muscle cell calcium activity that could be blocked by calcium entry blockers. A lack of response to EDRF-dependent vasodilators, as a result of ischemic endothelial injury, may contribute to the increased pressor sensitivity of the renal vessels.
\end{abstract}

\section{Introduction}

The pathogenesis of ischemic acute renal failure (ARF) ${ }^{1}$ involves both tubular and vascular abnormalities (1-4). In re-

This study has previously appeared in abstract form (1986. Proc. Am. Soc. Nephrol. 19:217A.).

Address all correspondence to Dr. John D. Conger, Veterans Administration Medical Center, 1055 Clermont Street, $111 \mathrm{c}$, Denver, CO 80220.

Received for publication 27 July 1987 and in revised form 3 March 1988.

1. Abbreviations used in this paper: ARF, acute renal failure; $\mathrm{CEB}$, calcium entry blockers; $C_{I N}$, inulin clearance; EDRF, endothelium-derived relaxing factor; GFR, glomerular filtration rate; $\mathrm{PGI}_{2}$, prostacyclin; RBF, renal blood flow; RNS, renal nerve stimulation; RPP, renal perfusion pressure; RVR, renovascular resistance.

The Journal of Clinical Investigation, Inc.

Volume 82, August 1988, 532-537 cent years, the tubular abnormalities have been intensively studied (5-8), while the vascular abnormalities have received less attention $(9,10)$. It has become clear, however, that an ischemic renal injury sufficient to cause reversible ARF is associated with abnormal renovascular reactivity in both the dog (10) and rat (9). Paradoxical vasoconstriction to a reduction in renal perfusion pressure (RPP) in the normal autoregulatory range, hypersensitivity to renal nerve stimulation (RNS), and loss of the renal vasodilatory effect of acetylcholine have been described (9). These vascular phenomena have been proposed to provide a potential explanation for the clinical observation that fresh tubular necrotic lesions have been demonstrable in renal tissues as late as $4 \mathrm{wk}$ after the overt clinical episode causing the ARF (11). Thus, subclinical ischemic episodes may cause tubular necrosis in a kidney recovering from ARF because of a renal vasoconstriction to relatively small reductions in RPP, hypersensitivity to RNS, and loss of renal vasodilatory influences. Support for this possibility has been reported recently in the rat where transient reduction in mean RPP from 120 to $90 \mathrm{mmHg}$ caused recurrent azotemia and fresh areas of necrosis in ARF rats (12).

The present study was undertaken to further examine the vascular abnormalities of experimental ARF. On the basis of the morphological evidence of vascular damage associated with renal ischemic injury (13), the hypothesis was examined that the abnormal pressor response to a reduction in RPP in the normal autoregulatory range, and hypersensitivity to RNS involved an increase in cellular calcium analogous to that which occurs in the renal tubule during the reflow phase of ischemic ARF (6). In this regard, an increase in cellular calcium and the calcium-calmodulin complex are important in the contractile process of vascular smooth muscle (14). To test this hypothesis, the effects of two chemically dissimilar calcium entry blockers (CEB) on the pressor response to a reduction in RPP and RNS in 7-d ischemic ARF rats were examined. Moreover, the possibility was examined that the absence of the vasodilatory response to acetylcholine in ischemic ARF was due to endothelial damage and loss of endothelium-derived relaxing factor (EDRF) activity (15), as it has been reported to be the case in the postischemic coronary circulation (16). An absence of response to EDRF may effectively be similar to removing the attenuating effert of endothelium in renovascular reactivity (17). The renal response to EDRF-dependent and -independent vasodilators was examined in 7-d ischemic ARF rats.

\section{Methods}

The disease model, NE-induced ARF, has been described previously (18). Briefly, adult Sprague-Dawley rats weighing 250-300 g underwent right nephrectomy $10 \mathrm{~d}$ before disease inducticn. After pentobarbital anesthesia, the left renal pedicle was exposed through a small flank incision. A micropipette (OD $35 \mu \mathrm{m}$ ) mounted on a micromanipulator and attached to a motor-driven syringe containing NE was introduced into the renal artery. NE was delivered at $0.6 \mu \mathrm{g} / \mathrm{kg} \cdot \mathrm{min}^{-1}$ for $90 \mathrm{~min}$. The micropipette was removed, the surgical wound closed, 
and the rats were returned to metabolic cages. They received water ad lib. and a low potassium diet (ICN Pharmaceuticals, Cleveland, $\mathrm{OH}$ ) for $72 \mathrm{~h}$ and a standard rat chow diet (Wayne Feed, Longmont, $\mathrm{CO}$ ) thereafter. Peak azotemia (blood urea nitrogen $120 \pm 11 \mathrm{mg} / \mathrm{dl}$ ) occurred between 24 and $48 \mathrm{~h}$ after NE infusion, remained stable over the next $3 \mathrm{~d}$, and fell gradually to control levels over the next 14-20 d (18). Renal blood flow (RBF) fell to zero at the time of NE infusion, returned to $70 \%$ of control levels by $24 \mathrm{~h}$, and gradually rose to control levels by $1 \mathrm{wk}$. Inulin clearance $\left(\mathrm{C}_{\mathrm{IN}}\right)$ fell to zero after NE infusion and slowly rose to $40 \%$ of control at 1 wk and $85 \%$ of control by 3 wk. Oliguria relative to control was present for $48 \mathrm{~h}$ after NE infusion and varied from continued oliguria to polyuria thereafter (19).

The technique of measuring renal vascular reactivity was described previously (9) and carried out as follows: at $1 \mathrm{wk}$, the rats were anesthetized with pentobarbital, $60 \mathrm{mg} / \mathrm{kg}$ i.p. after solid food had been withheld overnight. An endotracheal tube was positioned and catheters were placed in the right jugular vein and the femoral artery. The left kidney was exposed through a flank incision, the renal artery dissected bluntly from the renal vein, and a catheter was placed in the ureter. Blood pressure was measured through the right femoral artery catheter, which was connected to an electronic transducer (PD23DE; Statham Instruments, Oxnard, CA), and a direct-writing recorder (7702B; Hewlett-Packard Co., Palo Alto, CA). Ringer's lactate, containing an amount of inulin sufficient to give plasma concentrations of 50-100 $\mathrm{mg} / \mathrm{dl}$, was infused at $2 \mathrm{ml} / \mathrm{h}$ through the jugular venous catheter. After $1 \mathrm{~h}$ of equilibration, blood and urine samples were collected for $\mathrm{C}_{\mathrm{IN}}$ measurements. Spontaneous systemic blood pressures were in the range of 120-126 mmHg in ARF rats. RPP was controlled by placing a pliable small-gauge platinum wire about the aorta above the renal artery. Alterations in RBF were determined at RPP of 120,110,100, and $90 \mathrm{mmHg}$. The autoregulatory range of RBF in the rat has previously been demonstrated to be between 90 and $140 \mathrm{mmHg}(20)$. The RBF was measured with a miniature flow probe (Carolina Medical Electronics, Inc., King, NC), which was placed around the renal artery and attached to a digital recorder. The flow probe calibration was conducted according to the method of Arendshorst et al. (21). RBF was recorded 2 min after RPP was stabilized at each respective pressure. Measurements were made in duplicate.

After determinations of the RBF response to reduction in RPP, the effect of RNS on RBF was measured. The left renal nerve bundle was isolated near the aorta, crushed centrally and placed over a small insulated stainless steel hook electrode for nerve stimulation with a stimulus isolation unit (SIU5; Grass Instrument Co., Quincy, MA) (9). The nerve bundle was isolated by surrounding it with a Parafilm sheet for a distance of $1 \mathrm{~cm}$. Stimulator settings were as follows: electromotive forces $3 \mathrm{~V}$, duration of $50 \mathrm{~ms}$, delay $50 \mathrm{~ms}$, frequency of stimulation from 0 to $10 \mathrm{~Hz}$ at $2-\mathrm{Hz}$ intervals. $\mathrm{RBF}$ was recorded after $2 \mathrm{~min}$ of stimulation. It was allowed to return to control between stimulation periods.

\section{Protocol 1}

Effect of CEBs. 12 uninephrectomized rats were prepared for ischemic ARF induction with NE given directly into the renal artery as described above. 12 additional rats were similarly prepared but were given $0.9 \%$ saline rather than $\mathrm{NE}$ at the same rate. 1 wk later, both NE-ARF and sham-ARF control rats were prepared for reduction in RPP and RNS experiments as described above. RBF responses to baseline and serial reduction in RPP and RNS were then determined as control responses. After these measurements, the renal artery infusion was changed to verapamil, $6.0 \mu \mathrm{g} / \mathrm{kg}$ per $\mathrm{min}^{-1}$ in six NE-ARF and six control rats, or to diltiazem, $4.7 \times 10^{-2} \mu \mathrm{g} / \mathrm{kg}$ per $\mathrm{min}^{-1}$, in six NE$\mathrm{ARF}$ and six control rats. The infusion doses were the maximal intrarenal doses that did not alter systemic hemodynamics. After 90 min, RBF responses to reduction in RPP and RNS were repeated while the CEB infusion was continued.

In six additional NE-ARF rats, prostacyclin $\left(\mathrm{PGI}_{2}\right), 3 \times 10^{-4} \mu \mathrm{g} / \mathrm{kg}$ per $\min ^{-1}$ was added to the verapamil and diltiazem infusions after RBF response to a reduction in RPP was made as described above. To determine if there was residual vasodilatory capacity at the doses of verapamil and diltiazem chosen, $\mathrm{PGI}_{2}$ was added. 30 min after $\mathrm{PGI}_{2}$ was added, baseline RBF and RBF response to a reduction in RPP from 110 to $90 \mathrm{mmHg}$ were measured.

\section{Protocol 2}

Effect of EDRF-dependent and-independent vasodilators. In a separate group of 1-wk NE-ARF rats $(n=18)$, control RBF responses to serial reductions in RPP and RNS were measured after $90 \mathrm{~min}$ of intrarenal saline infusion as described in protocol 1 . Thereafter, the infusion was changed to acetylcholine, $1.28 \times 10^{-2} \mu \mathrm{g} / \mathrm{kg}$ per $\mathrm{min}^{-1}$ in six rats; bradykinin, $0.5 \mu \mathrm{g} / \mathrm{kg}$ per $\mathrm{min}^{-1}$ in six rats; and $\mathrm{PGI}_{2}, 3 \times 10^{-4} \mu \mathrm{g} / \mathrm{kg}$ per $\min ^{-1}$ in the remaining six rats. As in protocol 1 , doses infused were the maximal doses that would not alter systemic hemodynamics. After 90 min of infusion, RBF responses to reduction in RPP and RNS were repeated while the vasodilator infusion was continued.

\section{Analytical techniques and statistical analysis}

Plasma and urine inulin were measured with a Technicon autoanalyzer (Technicon Instruments Corp., Tarrytown, NY).

Data are expressed as means $\pm \mathrm{SD}$. Linear regression analysis was used to assess the relationship between RPP and RBF and the frequency of RNS. Since there were no differences between mean RBF in response to a reduction in RPP or RNS in NE-ARF or control rats before treatment with verapamil or diltiazem, cumulative means were calculated. Similarly, all preinfusion RBF values in response to a reduction in RPP and RNS were combined for the groups treated with EDRF-dependent and -independent vasodilators. Differences between control and vasoactive agent results in each protocol were compared by analysis of variance of the intercepts, mean slopes of regression lines, and absolute values as appropriate.

\section{Results}

Effects of CEBs on $R B F$ responses to reduction in $R P P$ and to $R N S$. The effects of verapamil and diltiazem on RBF responses to reduction in RPP in uninephrectomized sham-ARF control rats are shown in Fig. 1. Whole kidney glomerular filtration rate (GFR) was $1.20 \pm 0.06 \mathrm{ml} / \mathrm{min}$. The preinfusion slope of the RBF response in the sham-ARF control rats was slightly less than that which occurred with verapamil or diltiazem $(0.02 \pm 0.01$ vs. $0.06 \pm 0.02$ and $0.04 \pm 0.02 \mathrm{ml} / \mathrm{mmHg}$, respectively, both $P<0.025$ ). The changes in RVR between 120 and $90 \mathrm{mmHg}$ were $-2.8 \pm 0.2 \mathrm{mmHg} / \mathrm{ml}$ per min preinfusion, $-1.0 \pm 0.1 \mathrm{mmHg} / \mathrm{ml}$ per min with verapamil, and $-1.4 \pm 0.3$

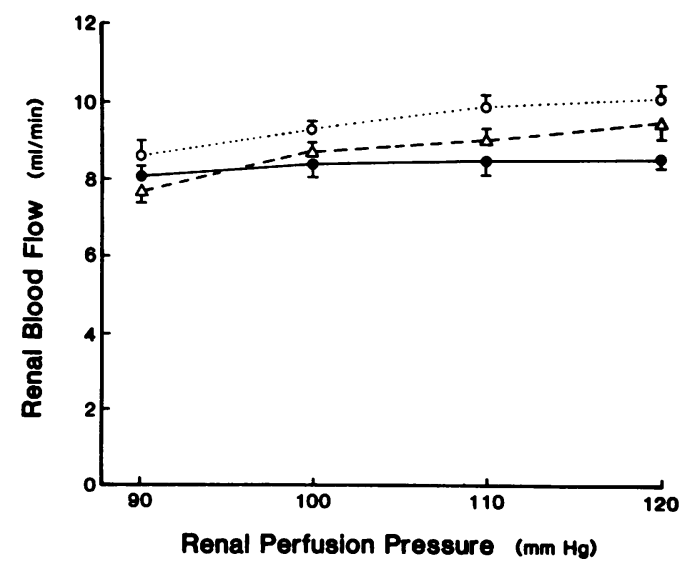

Figure 1. The response of RBF to sequential reduction in RPP before (closed circles) and after 90-min intrarenal infusion of verapamil (open triangles) or diltiazem (open circles) in sham-ARF control rats. 
$\mathrm{mmHg} / \mathrm{ml}$ per min with diltiazem. The latter two values differed from the former at $P<0.05$. Thus, RBF autoregulation was minimally, but significantly, attenuated in control rats because of the doses of verapamil and diltiazem used in this study. Both verapamil and diltiazem increased RBF from the preinfusion values at $120 \mathrm{mmHg}$ before the reduction in RPP (preinfusion, $8.60 \pm 0.20$ vs. verapamil, $9.50 \pm 0.40$ and diltiazem, $10.20 \pm 0.40 \mathrm{ml} / \mathrm{min}$, both $P<0.05$ ).

In NE-ARF rats infused with verapamil or diltiazem, whole kidney GFR was similar $(0.320 \pm 0.057$ vs. $0.257 \pm 0.124$ $\mathrm{ml} / \mathrm{min}$ ). In the NE-ARF rats, RBF with reduction in RPP before and after verapamil or diltiazem is shown in Fig. 2. Both CEBs attenuated the aberrant renal vasoconstrictor response to reduction in RPP. The respective slopes were: preinfusion, 0.18 \pm 0.02 ; verapamil, 0.04 \pm 0.02 ; and diltiazem, $0.04 \pm 0.01 \mathrm{ml} / \mathrm{mmHg}$. The CEB infusion values differed from the preinfusion values at $P<0.001$. The changes in RVR between 120 and $90 \mathrm{mmHg}$ were $30.3 \pm 4.1 \mathrm{mmHg} / \mathrm{ml}$ per min before infusion, $-1.4 \pm 1.1 \mathrm{mmHg} / \mathrm{ml}$ per min during verapamil, and $-1.8 \pm 1.2 \mathrm{mmHg} / \mathrm{ml}$ per min during diltiazem. As in sham-infused controls, both verapamil and diltiazem caused a slight but significant increase in RBF at the baseline pressure of $120 \mathrm{mmHg}$ before a sequential reduction in RPP compared with the corresponding preinfusion baseline value (verapamil, $9.40 \pm 0.08$ vs. $8.40 \pm 0.40 \mathrm{ml} / \mathrm{min}, P<0.025$; diltiazem, $9.70 \pm 1.20$ vs. $8.40 \pm 0.40 \mathrm{ml} / \mathrm{min}, P<0.05$ ). The slope of the preinfusion RBF response and the change in RVR in shamARF rats were less than the respective verapamil and diltiazem infusion values in NE-ARF rats $(P<0.05)$, which indicates that, while CEB markedly blunted the vasoconstriction to reduction in RPP in NE-ARF rats, they did not restore normal autoregulation.

The addition of $\mathrm{PGI}_{2}$ to the renal infusate after $90 \mathrm{~min}$ of verapamil or diltiazem demonstrated that the kidney vasculature in NE-ARF rats was not completely dilated by CEB agents. At $110 \mathrm{mmHg}$, the addition of $\mathrm{PGI}_{2}$ increased $R B F$ from $7.90 \pm 0.10$ to $8.90 \pm 0.20 \mathrm{ml} / \mathrm{min}(P<0.001)$ in verapamil-infused animals. Similarly, $\mathrm{PGI}_{2}$ increased $\mathrm{RBF}$ from $8.40 \pm 0.20$ to $8.80 \pm 0.20 \mathrm{ml} / \mathrm{min}(P<0.01)$ in diltiazem-infused rats.

The $\mathrm{RBF}$ responses to RNS in sham-ARF control rats are

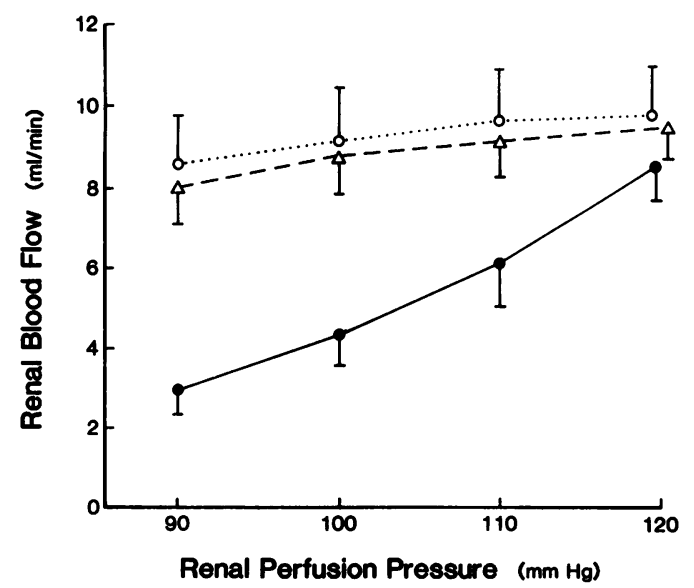

Figure 2. The response of RBF to sequential reduction in RPP before (closed circles) and after 90 -min intrarenal infusion of verapamil (open triangles) or diltiazem (open circles) in NE-ARF rats.

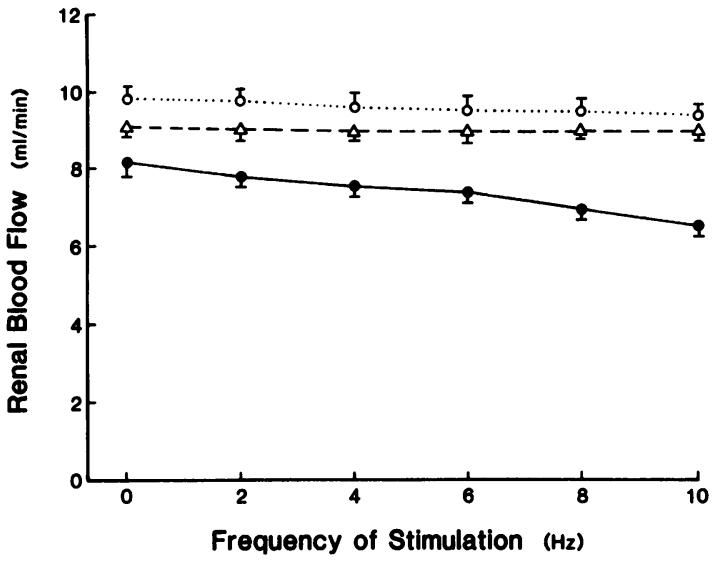

Figure 3. The response of RBF to increasing frequency of RNS before (closed circles) and after 90-min intrarenal infusion of verapamil (open triangles) or diltiazem (open circles) in sham-ARF control rats.

shown in Fig. 3. The slope of the preinfusion RBF to progressive stimulation was $0.17 \pm 0.05 \mathrm{ml} / \mathrm{Hz}$. Verapamil infusion effectively blocked the vasoconstrictor response to RNS (slope $1.01 \pm 0.02 \mathrm{ml} / \mathrm{Hz} ; P<0.001$ compared with the preinfusion value). Diltiazem also attenuated the preinfusion response to RNS (slope 0.04 $\pm 0.02 \mathrm{ml} / \mathrm{Hz}, P<0.001$ ).

In Fig. 4 the RBF responses to RNS before and after verapamil or diltiazem infusion in NE-ARF rats are illustrated. The vasoconstriction to progressive increments in RNS frequency before CEB infusion was significantly greater than the corresponding response to RNS in sham-ARF control rats $(P$ $<0.001)$. Vasoconstriction to RNS in NE-ARF rats was similarly blunted by either verapamil or diltiazem. The preinfusion slope was $0.56 \pm 0.08 \mathrm{ml} / \mathrm{Hz}$; with verapamil it was $0.02 \pm 0.01$ $\mathrm{ml} / \mathrm{Hz}$, and with diltiazem it was $0.07 \pm 0.08 \mathrm{ml} / \mathrm{Hz}$. The slopes with verapamil and diltiazem were significantly less than the respective preinfusion slopes at $P<0.001$. Before RNS, at a baseline RPP of $120 \mathrm{mmHg}$, preinfusion RBF was $8.40 \pm 0.50$ $\mathrm{ml} / \mathrm{min}$; during verapamil, $9.40 \pm 0.90 \mathrm{ml} / \mathrm{min}$, and during diltiazem, $9.70 \pm 1.20 \mathrm{ml} / \mathrm{min}$. RBF after verapamil and diltiazem 
was greater than the preinfusion value at $P<0.05$. The $\mathrm{RBF}$ responses to RNS with verapamil and diltiazem were similar in sham-ARF and NE-ARF rats.

Effect of EDRF-dependent and -independent vasodilators on $R B F$ responses to a reduction in RPP and to RNS. Whole kidney GFR values were not significantly different in NE-ARF kidneys given acetylcholine, bradykinin, or $\mathrm{PGI}_{2}$ : $0.396 \pm 0.122,0.275 \pm 0.096$, and $0.205 \pm 0.82 \mathrm{ml} / \mathrm{min}$, respectively. Neither the EDRF-dependent vasodilator, acetylcholine, nor bradykinin altered baseline RBF or RBF responses significantly over the range of blood pressures examined during reduction in RPP when compared with the untreated NEARF animals as shown in Fig. 5. The respective intercepts and slopes were: preinfusion, $8.40 \pm 0.40$ and $0.18 \pm 0.02$; acetylcholine, $8.40 \pm 0.53$ and $0.19 \pm 0.02$, and bradykinin, $8.67 \pm 0.65$ $\mathrm{ml} / \mathrm{min}$ and $0.19 \pm 0.02 \mathrm{ml} / \mathrm{mmHg}$. In contrast, $\mathrm{PGI}_{2}$, an EDRF-independent vasodilator, significantly increased RBF over a comparable range of blood pressures; however, it did not alter the paradoxical renal vasoconstrictor response to reduction in RPP in the NE-ARF kidney. The preinfusion RBF of $8.40 \pm 0.40 \mathrm{ml} / \mathrm{min}$ at $120 \mathrm{mmHg}$ was increased to $11.30 \pm 0.87 \mathrm{ml} / \mathrm{min}$ by $\mathrm{PGI}_{2}$. The slope of $\mathrm{RBF}$ to reduction of RPP of $0.22 \pm 0.02 \mathrm{ml} / \mathrm{mmHg}$ was similar to the preinfusion value of $0.18 \pm 0.02 \mathrm{ml} / \mathrm{mmHg}$.

Progressive increases in RNS decreased RBF to the same extent whether in the absence or presence of the EDRF-dependent vasodilators, acetylcholine and bradykinin (Fig. 6). The intercepts and slopes for acetylcholine $(8.50 \pm 0.50 \mathrm{ml} / \mathrm{min}$ and $0.60 \pm 0.09 \mathrm{ml} / \mathrm{Hz}$ ) and bradykinin $(8.85 \pm 0.46 \mathrm{ml} / \mathrm{min}$ and $0.65 \pm 0.15 \mathrm{ml} / \mathrm{Hz}$ ) were not different from the preinfusion values $(8.40 \pm 0.50 \mathrm{ml} / \mathrm{min}$ and $0.56 \pm 0.08 \mathrm{ml} / \mathrm{Hz})$. While the EDRF-independent vasodilator, $\mathrm{PGI}_{2}$, increased the level of RBF at each level of RNS, the slope of the response was actually slightly greater than the preinfusion value. The respective intercepts were $8.40 \pm 0.50 \mathrm{ml} / \mathrm{min}$ preinfusion and $11.30 \pm 0.87 \mathrm{ml} / \mathrm{min}$ during $\mathrm{PGI}_{2}$ (different at $P<0.001$ ). The slopes were $0.56 \pm 0.08 \mathrm{ml} / \mathrm{Hz}$ preinfusion and $0.84 \pm 0.19$ $\mathrm{ml} / \mathrm{Hz}$ (different at $P<0.05$ ).

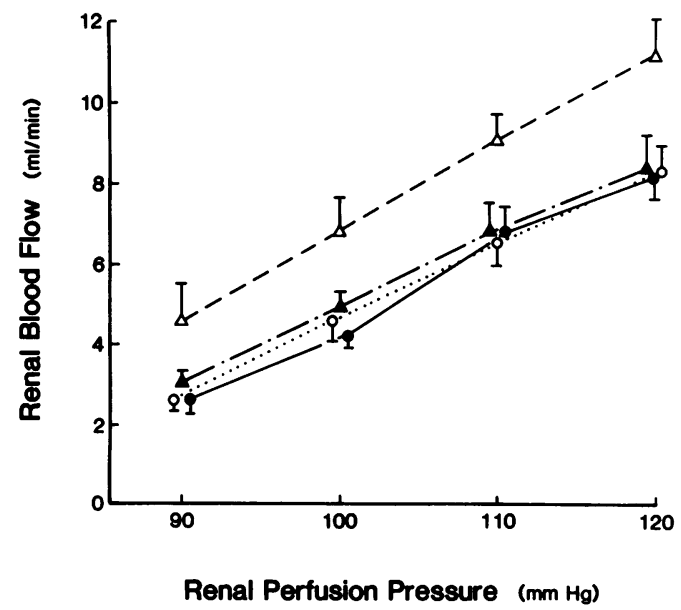

Figure 5. The RBF response to sequential reduction in RPP before (closed circles) and after 90-min intrarenal infusion of EDRF-dependent vasodilators, acetylcholine (open circles) and bradykinin (closed triangles) or EDRF-independent vasodilator, $\mathrm{PGI}_{2}$ (open triangles) in NE-ARF rats.

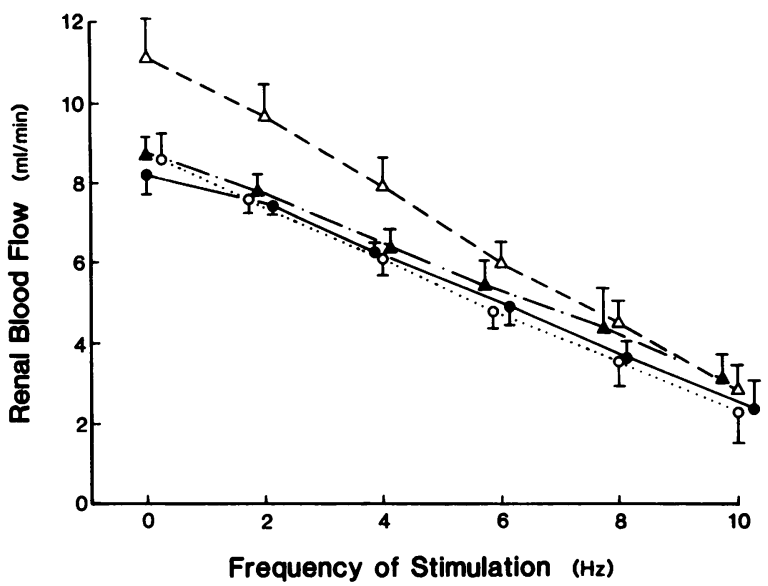

Figure 6. The RBF response to increasing frequency of RNS before (closed triangles) and after 90-min intrarenal infusion of EDRF-dependent vasodilators, acetylcholine (open circles) and bradykinin (closed triangles) or $\mathrm{PGI}_{2}$ (open triangles) in NE-ARF rats.

\section{Discussion}

Although RBF is maintained at a reasonable level (50-75\% of normal) even in the presence of ARF (18), it is nevertheless possible that persistent vascular abnormalities may contribute to the duration of ARF before recovery. Specifically, the paradoxical renal vasoconstrictor response to reduction in RPP and hypersensitivity to RNS could mediate recurrent tubular necrosis and thus sustain persistent tubular dysfunction during the maintenance phase of ARF. Thus, subclinical alterations in systemic blood pressure, which would not affect renal perfusion in normal physiologic circumstances, could cause renal ischemia and tubular necrosis in the ARF kidney, which exhibits vasoconstriction to reduction in RPP in the normal autoregulatory range and hypersensitivity to RNS. Indeed, the documentation that fresh tubular necrosis may be observed as late as 4 wk after the onset of ARF in patients (11) is compatible with this possibility. Moreover, the observation that in 7-d NE-induced ARF rats a lowering of RPP within the autoregulatory range is associated with tubular necrosis and the worsening of azotemia, while no detectable changes occur in normal rats, also supports this possibility (12).

Since intracellular calcium is known to be an important mediator of vascular contractility (14), and CEBs are known to attenuate experimental ARF in animals (22) as well as enhance cadaver graft survival in patients (23), the possibility exists that some of the vascular abnormalities in ischemic ARF may be modulated by perturbations in cell calcium. The recent observation that ischemic injury to the kidney is associated with vascular damage (13) is compatible with the recent suggestion that enhanced intracellular calcium influx alters renal vascular tone and responsiveness in ischemic ARF (5). An alternative or additional pathological result of ischemia-induced vascular damage might, however, be that endogenous EDRF-dependent renal vasodilators such as acetylcholine and bradykinin are not able to modify ischemic insults in the ARF kidney, which is similar to the recent observations that have been made with acetylcholine in the postischemic coronary circulation (16). 
The observation in the present study that two chemically different CEBs, verapamil and diltiazem, afford protection against some of the vascular abnormalities associated with ischemic ARF is compatible both with the role of cellular calcium in these vascular smooth muscle abnormalities of ischemic ARF as well as with a vascular role for CEBs in preventing experimental ischemic ARF. In this regard, it has been suggested that a vascular rather than a cytoprotective tubular effect mediates the in vivo protective effect of CEBs against ischemic ARF (24). While the present results do not exclude the possibility of a solitary effect of CEBs on tubular epithelium, a possibility for which there is considerable evidence, these findings are clearly in support of important vascular effects of these agents in the attenuation of ischemic ARF. As with the protective effect against ischemic ARF, the intrarenal delivery and the duration of the infusion of the CEBs are of potential importance. In the present study, 90 , but not 30 , min of intrarenal verapamil or diltiazem blocked the renal vasoconstrictor response to reduction in RPP and attenuated the hypersensitivity to RNS. Similarly, in a previous study, $2 \mathrm{~h}$, but not $30 \mathrm{~min}$, of intrarenal verapamil or nifedipine attenuated ischemic ARF induced by NE in the dog (22). Also of interest is the observation that intrarenal CEBs decrease tubular sodium reabsorption in the normal dog (25), whereas the known diminution in tubular sodium reabsorption associated with ischemic ARF is significantly attenuated by CEBs (26). Such observations are compatible with profoundly different cellular calcium kinetics in normal, as compared with ischemically injured, vascular smooth muscle and tubular epithelium.

It must be pointed out that while verapamil and diltiazem blocked the renal vasoconstrictor response in the NE-ARF rats, these agents had little effect on normal RBF autoregulation in the sham-ARF control rats. While there was a progressive decline in RVR with reduction in RPP in the sham-ARF control rats before CEB infusion, this fall in RVR was significantly attenuated by verapamil and diltiazem. The RVR changes that occur with a reduction in RPP during verapamil and diltiazem infusion in NE-ARF rats were also less than those of the preinfusion decline in RVR in sham-ARF controls. CEBs have been shown by others to reduce autoregulatory capacity in rat and dog kidneys $(27,28)$. Nevertheless, the striking effect of the CEB was that these agents blocked the paradoxical renal vasoconstriction to reduction in RPP in NE-ARF rats. Lastly, it should be noted that the ability of $\mathrm{PGI}_{2}$ to increase $R B F$ in verapamil-infused kidneys in this study indicates that there was potential for further vasodilatation in the CEB-infused kidneys with reduction in RPP.

The present results also provide a potential explanation for the previous observation that ischemia-induced ARF kidneys in the rat do not respond to acetylcholine (9). Since the vasodilator effect of acetylcholine is dependent upon the presence of an endothelium-derived substance (EDRF) $(15,29)$ and the renal vascular endothelium is injured after an acute ischemic insult (13), failure to synthesize or release EDRF could potentially mediate this resistance to acetylcholine. The observation that bradykinin, another EDRF-dependent vasodilator (30), also did not increase RBF in the ischemic ARF kidneys provided further support for this possibility. Moreover, $\mathrm{PGI}_{2}$, an EDRF-independent vasodilator (15), was shown to vasodilate the ARF kidneys. These findings also supported the possibility of a unique role for CEBs in the above described vascular abnormality of ischemic ARF. Although $\mathrm{PGI}_{2}$ caused vasodilatation in this setting, it did not block the vasoconstrictor response to reduction in RPP in the ARF rats. The potential importance of preservation of the vasodilatory response to $\mathrm{PGI}_{2}$ in the ischemically injured kidney, is supported by the observations that inhibition of prostaglandin synthesis may cause ARF in settings such as cirrhosis (31), cardiac failure (32), volume depletion (33), and lupus nephritis (34); circumstances known to be associated with increased renal vascular resistance.

In conclusion, the observations that two chemically dissimilar CEBs abolished the paradoxical vasoconstriction to reduction in RPP and hypersensitivity to RNS in ischemic ARF support a role of perturbation in vascular smooth muscle cellular calcium in the pathogenesis of these vascular abnormalities. These findings suggest that the protective effect of CEBs against ischemic ARF may be mediated, at least in part, by effects of vascular smooth muscle. The endothelial damage associated with ischemic ARF is also of importance because the response to endogenous EDRF-dependent renal vasodilators such as acetylcholine and bradykinin is impaired, while the response to the EDRF-independent, endogenous renal vasodilator, prostacyclin, is preserved.

\section{Acknowledgments}

The authors thank Sue Wolf for her assistance in preparing this manuscript.

These studies were supported by National Institute of Health grant DK-35098, Veterans Administration research funds, and U.S. Army Contract DAMD 17-85C-5288. Injectable diltiazem was kindly supplied by Marion Laboratories, Kansas City, MO.

\section{References}

1. Schrier, R. W., P. E. Arnold, V. J. Van Putten, and T. J. Burke. 1988. Pathophysiology of cell ischemia. In Diseases of the Kidney. R. W. Schrier and C. W. Gottschalk, editors. Little, Brown and Co., Boston. 1379-1412.

2. Stein, J. H., D. Meyer, L. Lifschitz, and L. D. Barnes. 1978. Current concepts on the pathophysiology of acute renal failure. Am.J. Physiol. 234:F171-F181.

3. Williams, R. H., C. E. Thomas, L. G. Navar, and A. P. Evans. 1981. Hemodynamic and single nephron function during the maintenance phase of ischemic acute renal failure in the dog. Kidney Int. 19:505-515.

4. Conger, J. D. 1983. Vascular abnormalities in the maintenance of acute renal failure. Circ. Shock. 11:235-244.

5. Humes, H. D., and J. M. Weinberg. 1983. Cellular energetics in acute renal failure. In Acute Renal Failure. B. M. Brenner and J. M. Saunders, editors. W. B. Saunders Co., Philadelphia. 47-98.

6. Arnold, P. E., V. J. Van Putten, D. Lumlertgul, T. J. Burke, and R. W. Schrier. 1986. Adenonine nucleotide metabolism and mitochondrial $\mathrm{Ca}^{2+}$ transport following renal ischemia. Am. J. Physiol. 250:F357-F363.

7. Schrier, R. W., P. E. Arnold, J. A. Gordon, and T. J. Burke. 1984. Protection of mitochondrial function by mannitol in ischemic acute renal failure. Am. J. Physiol. 247:F365-F379.

8. Weinberg, J. M. 1985. Oxygen deprivation-induced injury to isolated rabbit kidney tubules. J. Clin. Invest. 26:1193-1208.

9. Kelleher, S. P., J. B. Robinette, and J. D. Conger. 1984. Sympathetic nervous system in the loss of autoregulation in acute renal failure. Am. J. Physiol. 246:F379-F386.

10. Adams, P. L., P. F. Adams, P. D. Bell, and L. G. Navar. 1980. 
Impaired renal blood flow autoregulation in ischemic acute renal failure. Kidney Int. 18:68-76.

11. Solez, L., L. Morel-Maroger, and J. Sraer. 1979. The morphology of "acute tubular necrosis" in man: analysis of 57 renal biopsies and comparison with the glycerol model. Medicine (Baltimore). $58: 362-376$.

12. Kelleher, S. P., J. B. Robinette, F. Miller, and J. D. Conger. 1987. Effect of hemorrhagic reduction in blood pressure on recovery from acute renal failure. Kidney Int. 31:725-730.

13. Matthys, E., M. Patton, R. Osgood, M. Venkatachalam, and J. Stein. 1983. Alterations in vascular function and morphology in ischemic ARF. Kidney Int. 19:399-409.

14. Van Breeman, C., C. Cauvin, A. Johns, P. Leijten, and H. Yamamot. 1986. $\mathrm{Ca}^{2+}$ regulation of vascular smooth muscle. Fed. Proc. 45:2746-2750.

15. Furchgott, R. F. 1983. Role of endothelium in responses of vascular smooth muscle. Circ. Res. 53:557-573.

16. Van Benthuysen, K. M., I. F. McMurty, and L. D. Horwitz. 1987. Reperfusion after acute coronary occlusion in dogs impairs endothelium-dependent relaxation to acetylcholine and augments contractile reactivity in vitro. J. Clin. Invest. 79:265-274.

17. Lamping, K. G., M. L. Marcus, and W. P. Dole. 1985. Removal of the endothelium potentiates canine large coronary artery constrictor responses to 5-hydroxytryptamine in vivo. Circ. Res. 57:46-54.

18. Conger, J. D., J. B. Robinette, and S. P. Kelleher. 1984. Nephron heterogeneity in ischemic acute renal failure. Kidney Int. 36:422-429.

19. Conger, J. D., J. B. Robinette, and F. J. Guggenheim. 1981. Effect of acetylcholine on the early phase of reversible norepinephrine-induced acute renal failure. Kidney Int. 19:399-409.

20. Conger, J. D., and T. J. Burke. 1976. Effects of anesthetic agents on autoregulation of renal hemodynamics in the rat and dog. Am. J. Physiol. 230:652-657.

21. Arendshorst, W. J., W. F. Finn, and C. G. Gottschalk. 1979. Autoregulation of renal blood flow in the rat. Circ. Res. 44:344-349.

22. Burke, T. J., P. E. Arnold, J. A. Gordon, R. E. Bulger, D. C. Dobyan, and R. W. Schrier. 1984. Protective effect of intrarenal calcium membrane blockers before or after renal ischemia. Functional, morphological, and mitochondrial studies. J. Clin. Invest. 74:18301841.

23. Wagner, K., S. Albrecht, and H. H. Neumayer. 1986. Prevention of delayed graft function in cadaveric kidney transplantation by a calcium antagonist. Preliminary results of two prospective trials. Transplant. Proc. 18:510-515.

24. Malis, C. D., J. Y. Cheung, and A. L. Leaf. 1983. Effects of verapamil in models of ischemic acute renal failure in the rat. $\mathrm{Am}$. J. Physiol. 245:F735-F742.

25. McCrorey, H. L., T. Berl, T. J. Burke, A. de Torrente, and R. W. Schrier. 1980. Effect of calcium transport inhibitors on renal hemodynamics and electrolyte excretion in the dog. In Hormonal Regulation of Sodium Excretion. B. Lichardus, R. W. Schrier, and J. Ponec, editors. Elsevier/North Holland Biomedical Press, Amsterdam. 113-120.

26. Shapiro, J. I., C. Cheung, A. Itabashi, L. Chan, and R. W. Schrier. 1985. The effect of verapamil on renal function after warm and cold ischemia in the isolated perfused rat kidney. Transplantation (Baltimore). 40:596-600.

27. Cohen, A. J., and J. C. S. Fray. 1982. Calcium ion dependence of myogenic renal plasma flow autoregulation: evidence from the isolated perfused rat kidney. J. Physiol. 330:449-460.

28. Ono, H., H. Kokubun, and K. Hashimoto. 1974. Abolition by calcium antagonists of the autoregulation of renal blood flow. Naunyn-Schmiedeberg's Arch. Pharmacol. 285:201-207.

29. Schipke, J. D., G. Heusch, and V. Thamar. 1985. Acetylcholine induces constriction of epicardial coronary arteries in anesthetized dogs after removal of endothelium. Arzneim.-Forsch. 35:926-929.

30. Cherry, P. D., R. F. Furchgott, J. V. Zawadzki, and D. Jothianandan. 1982. The role of endothelial cells in the relaxation of isolated arteries by bradykinin. Proc. Natl. Acad. Sci. USA. 79:21062110 .

31. Zipser, R. D., J. C. Hoefs, P. F. Speckart, P. K. Zia, and R. Horton. 1979. Prostaglandins: modulators of renal function and depressor resistance in chronic liver disease. J. Clin. Endocrinol. \& Metab. 48:895-900.

32. Blackshear, J. L., M. Davidman, and T. Stillman. 1983. Identification of risk for renal insufficiency from non-steroidal anti-inflammatory drugs. Arch. Intern. Med. 143:1130-1134.

33. Muther, R. S., D. M. Potter, and W. M. Bennett. 1981. Aspirin-induced depression of glomerular filtration rate in hormal humans: role of sodium balance. Ann. Intern. Med. 94:317-321.

34. Kimberly, R. P., R. E. Bowden, H. R. Keiser, and P. H. Plotz. 1978. Reduction of renal function by newer non-steroidal anti-inflammatory drugs. Am. J. Med. 64:804-807. 